RASĀYAN J. Chem.

Vol. 14 | No. 2 |1165-1174| April - June | 2021

ISSN: 0974-1496 | e-ISSN: 0976-0083 | CODEN: RJCABP

http://www.rasayanjournal.com

http://www.rasayanjournal.co.in

\title{
THE EFFECT OF FUNCTIONAL GROUP IN POLYEUGENOL FOR UREA, CREATININE AND VITAMIN B12 TRANSPORT
}

\author{
M.C. Djunaidi ${ }^{1, \bigotimes}$ and I.G. Wenten ${ }^{2}$ \\ ${ }^{1}$ Department of Chemistry, Diponegoro University, 50275, Indonesia \\ ${ }^{2}$ Department of Chemical Engineering, Bandung Institute of Technology, 40132, Indonesia \\ ${ }^{\bowtie}$ Corresponding Author: choliddjunaidi@live.undip.ac.id
}

\begin{abstract}
The effect of functional group in polyeugenol based membrane study has been done. The objective of this research is to synthesis a membrane based on eugenol and its derivative to see the influence of the functional group regarding the membrane transport performance for hemodialysis usage. Polyeugenol, Poly Pyridine Methyl Eugenoxy Acetate, and Poly Methyl Thiazole Ethyl Eugenoxy Acetate were synthesized by an in-situ method using Poly Vinyl Alcohol mixed with Sodium Hydroxide and Poly Ethylene Glycol Diglicidyl Ether as the crosslinker. The mixture was made into a gel by heating at $110^{\circ} \mathrm{C}$. It was then reconstituted, made into a membrane, and washed. The resulted membrane was characterized and used to transport urea, creatinine, and vitamin $\mathrm{B}_{12}$. The variations used were the functional group, the feed phase (urea, creatinine, and vitamin $\mathrm{B}_{12}$ ), and the membrane performance in contrast with the non-imprinted membrane. According to the results, it was found that the imprinted membranes were more able to transport urea, creatinine, and vitamin $\mathrm{B}_{12}$ compared to the non-imprinted membrane. It was also proven that the membrane with the hydroxyl group is better than the other group for urea transport and the membrane with a thiazole group has a better ability to transport vitamin $\mathrm{B}_{12}$ compared to the membranes with hydroxyl or pyridine groups.
\end{abstract}

Keywords: Molecularly imprinted polymer, Eugenol, Hemodialysis, Urea, Creatinine, Vitamin $\mathrm{B}_{12}$

RASĀYAN J. Chem., Vol. 14, No.2, 2021

\section{INTRODUCTION}

Recently, hemodialysis is one of the most important products of biomaterial application which includes contacts with human blood. The core of the hemodialysis system is its semipermeable membrane. To be categorized as a qualified semipermeable membrane for hemodialysis, it needs to not be able to escape protein or cells but able to escapes urea molecules in the blood. It is also expected to have good mechanical strength, high resistance, and biocompatibility. Hydrophilic and hydrophobic equilibrium is also expected. ${ }^{1}$ Due to cellulose limitations and its derivatives, studies about the hemodialysis membrane evolve. Cellulose, chitosan, and polysulfone based membrane have its shortcoming as it still lets the blood protein get inside the surface, heparin which could damage the blood cells were added to overcome this. ${ }^{2,3}$

Indonesia is a country with many potentials in natural resources as it has a very large forest area with a various diversity of plants. This leads Indonesia as one of the largest essential oil producers in the world. Indonesia has continuously export cloves to 21 countries, although the export volume fluctuated over the years, the average volume still showed a continued increasement. ${ }^{4}$ Although being the largest essential oils producer, it has not been used to its full potential yet. One of the essential oils that are still able to be explored more is cloves leaf oil. Eugenol is contained in cloves leaf oil around $80-90 \%$ by weight. ${ }^{5}$ In a synthesis, eugenol could be used as the starting material due to the three functional groups that it possessed, which are allyl, hydroxy, and methoxy groups. Derivates of eugenol such as polyeugenol and polyeugenoxy acetate have been successfully applied as liquid membrane carriers that have good selectivity and could be modified based on the used functional group. ${ }^{6-9}$

Eugenol could also be used as the functional monomer of a molecularly imprinted polymer (MIP) with good selectivity because of its three functional groups. Polyeugenol has been used as the functional monomer of a membrane with the help of a crosslinker. MIP Fe, MIP phenol, MIP vanillin, and MIP glucose were synthesized and they all showed good selectivity ability. ${ }^{6,910}$ MIP phenol was able to 
RASĀYAN J. Chem.

Vol. 14 | No. 2 |1165-1174| April - June | 2021

selectively adsorb phenol far better than compounds with vanillin-like structures and MIP glucose was able to adsorb glucose but not fructose although both have the same molecular weight and only differentiated by their functional group. Djunaidi synthesized a Fe IIP membrane that was non-porous, elastic, strong enough, or has good resistance, and showed good selectivity towards Fe (III). The membrane showed better transport of Fe (III) compared to the other metals that were used, thus proven its selectivity properties ${ }^{7}$. Djunaidi also synthesized a polyeugenoxy acetic acid-based membrane with thionyl chloride for selective transport of urea. It was shown that the membrane has a better performance compared to the non-imprinted one and that the membrane was still able to transport creatinine but not vitamin $\mathrm{B}_{12 .}{ }^{11}$ In this study, we will synthesize various eugenol-based membranes and see their performance in selectively transport urea, creatinine, and vitamin $\mathrm{B}_{12}$.

\section{Materials}

\section{EXPERIMENTAL}

Eugenol and $\mathrm{BF}_{3}$-diethyl ether were purchased from SIGMA-Aldrich and the reagents purchased from Merck were $\mathrm{SOCl}_{2}$, 4-methyl-5-thiazole ethanol, chloroacetic acid, sodium hydroxide, chloroform, polyvinylalcohol (PVA), methanol, urea, creatinine, and vitamin $\mathrm{B}_{12}$. Materials purchased from Bratachem were diethyl ether and demineralized water.

\section{Instrumentation}

The instruments used in this research were FTIR Spectrophotometer (Shimadzu 8201PC), UV-Vis Spectrophotometer (Shimadzu), SEM EDX (JSM-6510), Analytical balance (Mettler Tolendo AB54-S), and $\mathrm{pH}$ meter (HACH E C20).

\section{Synthesis of Polyeugenol}

In a three-necked flask, $5 \mathrm{~g}$ of eugenol was added with $1 \mathrm{~mL}$ of $\mathrm{BF}_{3}$-diethyl ether and then stirred for 4 hours, and each hour, $\mathrm{BF}_{3}$-diethyl ether was added as much as $0.25 \mathrm{~mL}$. After 4 hours, the polymerization was ended by the addition of methanol as much as $1 \mathrm{~mL}$. It then formed a gel which was then dissolved by diethyl ether and further washed by distilled water until the $\mathrm{pH}$ becomes neutral. Afterward, anhydrous $\mathrm{Na}_{2} \mathrm{SO}_{4}$ was used to bind the water in the solution. When there is no remaining water left, the solution was let to evaporate the left chloroform at room temperature. The result was then weighed and characterized by FTIR.

\section{Synthesis of Polyeugenoxy Acetic Acid}

Polyeugenoxy acetic acid synthesis was done by adding $17.5 \mathrm{~mL}$ of $33 \% \mathrm{NaOH}$ solution into $5 \mathrm{~g}$ of polyeugenol. 30 minutes into stirring, $12.5 \mathrm{~mL}$ of $50 \%$ chloroacetic acid solution was added dropwise. The mixture is then heated at $80-90^{\circ} \mathrm{C}$ for 2 hours. Afterward, the mixture was let to cooled down and then added with $\mathrm{HCl} 6 \mathrm{M}$ until it reached $\mathrm{pH}$ 1. It is then followed with extraction using $50 \mathrm{~mL}$ of diethyl ether 3 times. The combined ether extracts were then further extracted using $30 \mathrm{~mL}$ of $5 \% \mathrm{w} / \mathrm{v}$ sodium bicarbonate 3 times. Then, the water layer was acidified until $\mathrm{pH} 1$. After the result is filtered, dried, and weighed, it was characterized with FTIR.

\section{Synthesis of Poly (Pyridine Methyl Eugenoxy Acetate) (PPMEOA)}

Eugenoxy acetic acid (EOA) as much as $3 \mathrm{~g}(0.0135 \mathrm{~mol})$ was added with $1.6 \mathrm{~mL}$ of thionyl chloride $(0.022 \mathrm{~mol})$ little by little. In a warm cooking oil bath, it was then refluxed for 150 minutes with a temperature of $40^{\circ} \mathrm{C}$. Afterward, once the mixture has cooled down, it was added with $2 \mathrm{~mL}(0.0207 \mathrm{~mol})$ of pyridyl carbinol drop by drop and then refluxed once more at the same temperature for 60 minutes. After it is finished and the mixture temperature has come down to room temperature, it was dissolved using chloroform and washed with water. The resulting product then dried with anhydrous $\mathrm{Na}_{2} \mathrm{SO}_{4}$, filtered, and then let to evaporate the chloroform left. Lastly, FTIR characterization was performed.

\section{Synthesis of Poly (Methyl Thiazoleethyl Eugenoxy Acetate) (PMTEEA)}

In a boiling flask, $3 \mathrm{~g}$ of EOA was mixed with $3 \mathrm{~mL}$ of thionyl chloride and refluxed for 4 hours $\left(40^{\circ} \mathrm{C}\right)$, and then allowed to cool. Afterward, an addition of $2.5 \mathrm{ml}$ of thiazole ethanol was done and then the 
RASĀYAN J. Chem.

Vol. 14 | No. 2 |1165-1174| April - June | 2021

mixture was refluxed again for another 4 hours $\left(40^{\circ} \mathrm{C}\right)$. After it has cooled down, it was then dissolved in chloroform followed by washing using water. Later on, the solution was added with anhydrous $\mathrm{Na}_{2} \mathrm{SO}_{4}$ and then filtered. After the product has evaporated all the remaining chloroform, the precipitate was then characterized by FTIR.

\section{Synthesis of In Situ MIP Membrane}

$0.5 \mathrm{~g}$ for each of PE, PPMEOA, and PMTEEA were contacted with $10 \mathrm{~mL}$ of $100 \mathrm{ppm}$ urea. The results were analyzed by FTIR after dried. $0.5 \mathrm{~g}$ of PVA that was dissolved in $5 \mathrm{~mL}$ of NMP was then added to PE, PPMEOA, and PMTEEA that have been contacted with urea. Sodium hydroxide and EGDE were then added, and the mixture was heated at $100-110^{\circ} \mathrm{C}$ for 4 hours and was let to form a gel overnight. NMP solvent was then added to the gel and it was heated to obtain the right viscosity that supports the casting process. Afterward, the casted membrane was heated at $80^{\circ} \mathrm{C}$ overnight and the result was coagulated for 2 days in $1.5 \mathrm{M} \mathrm{NaCl}$. The membrane was furthermore prepared by cutting it to the same size and shape as the diffusion cell and then washed with demineralized water. After cleaned, the urea was released with distilled water for 24 hours, producing urea MIP membrane, and then it was installed on the diffusion cell tool ring.

\section{Synthesis of NIP (Non-imprinted Polymer)}

The synthesis of NIP was done through the same method used in the synthesis of the urea MIP except without the first contacting step with urea. PE, PPMEOA, and PMTEEA were used without any contact with urea first.

Performance Comparison of MIP Membrane and NIP Membrane in Urea Transport

The membrane performance of $0.35 \mathrm{~g}$ MIP was compared to its performance with a $0.35 \mathrm{~g}$ NIP membrane in transporting urea with a concentration of $300 \mathrm{ppm}$.

\section{Transport of Urea}

The urea transport was performed for 24 hours with a diffusion cell. $100 \mathrm{mg} / \mathrm{L}$ of urea as much as $50 \mathrm{~mL}$ was used as the feed phase, while $50 \mathrm{~mL}$ of phosphate buffer $(\mathrm{pH} \mathrm{6.5)}$ was used as the receiving phase. the transport process was performed with stirring in both phases and the sample was taken at $2,4,6,8$, and 24 hours.

\section{Transport of Creatinine}

The creatinine transport was performed using a diffusion cell. $25 \mathrm{mg} / \mathrm{L}$ of creatinine as much as $50 \mathrm{~mL}$ was used as the feed phase, while $50 \mathrm{~mL}$ of phosphate buffer $(\mathrm{pH} \mathrm{6.5)}$ was used as the receiving phase. Stirring was carried out for 8 hours using a $0.35 \mathrm{~g}$ MIP membrane.

\section{Transport of Vitamin $B_{12}$}

The vitamin $\mathrm{B}_{12}$ transport by $0.35 \mathrm{~g}$ of MIP membrane utilizes a diffusion cell was performed with stirring for 6 hours. $20 \mathrm{mg} / \mathrm{L}$ of vitamin $B_{12}$ as much as $50 \mathrm{~mL}$ was used as the feed phase while $50 \mathrm{~mL}$ of phosphate buffer ( $\mathrm{pH} 6.5)$ was used as the receiving phase.

\section{Detection Method}

SEM-EDX Analysis

NIP and MIM were analyzed by SEM-EDX, before and after urea transport for 24 hours, and with MIP membranes washed for 1 and 24 hours.

\section{Synthesis of PPMEOA}

\section{RESULTS AND DISCUSSION}

At the absorption bands of 915,997 , and $1648-1638 \mathrm{~cm}^{-1}$ seen in Fig.-1, the disappearance of eugenol vinyl spectra was spotted which indicates that polymerization has taken place. The alcohol C-O group at the $1600 \mathrm{~cm}^{-1}$ wavenumber range was changed into the carbonyl acid group $(\mathrm{C}=\mathrm{O})$ which was shown in 
RASĀYAN J. Chem.

Vol. 14 | No. 2 |1165-1174| April - June | 2021

the absorption at $1735.93 \mathrm{~cm}^{-1}$ and the acidic $\mathrm{C}-\mathrm{O}$ was shown at the absorption of $1149.57 \mathrm{~cm}^{-1}$ and shifted into the carbonyl ester group $\left(1759.08 \mathrm{~cm}^{-1}\right)$ after the esterification reaction with 2Pyridinemethanol. The alcohol $(\mathrm{O}-\mathrm{H})$ group in eugenol and polyeugenol turned into PPMEOA acids and esters at around $3400 \mathrm{~cm}^{-1}$.

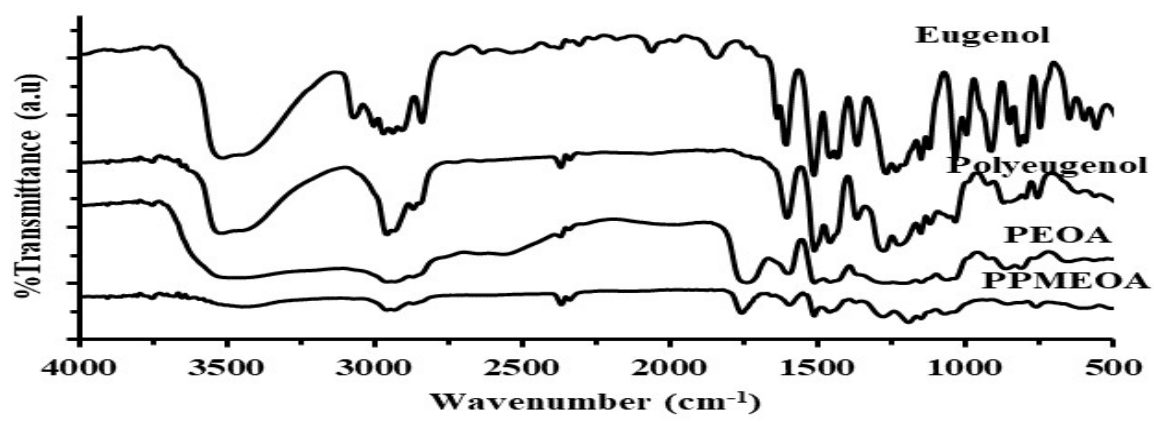

Fig.-1: IR Spectra of Eugenol and its Derivatives

\section{Synthesis of Urea Membrane}

PE that has been achieved was contacted with urea with a concentration of $100 \mathrm{ppm}$ and then analyzed with FTIR to prove the presence of urea in the polymer after contacting. The FTIR result can be seen in Fig.-2.

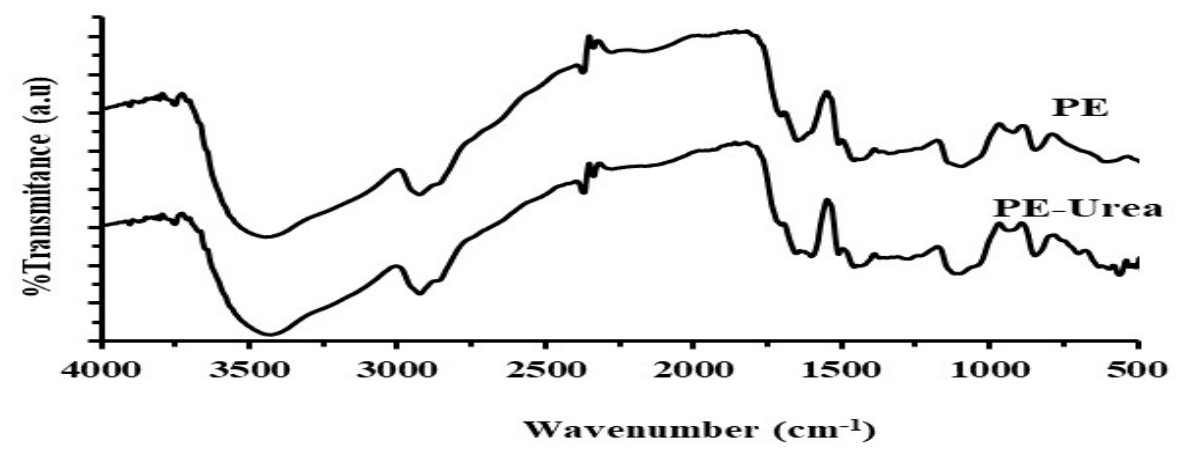

Fig.-2: Graph of FTIR Result Comparison between Polyeugenol (PE) and PE-Urea

In Fig.-2, the spectra appearance of N-H bending vibrations at $1604,77 \mathrm{~cm}^{-1}$ was seen. ${ }^{12}$ Which does not appear on PE NIP. Synthesized PPMEOA was contacted with $100 \mathrm{ppm}$ urea. The achieved results were analyzed with FTIR, as can be seen in Fig.-3. In Fig.-3, the appearance of $1604.77 \mathrm{~cm}^{-1}$ spectra is the bending vibration of $\mathrm{N}-\mathrm{H} .{ }^{12}$ Which does not appear on PPMEOA.

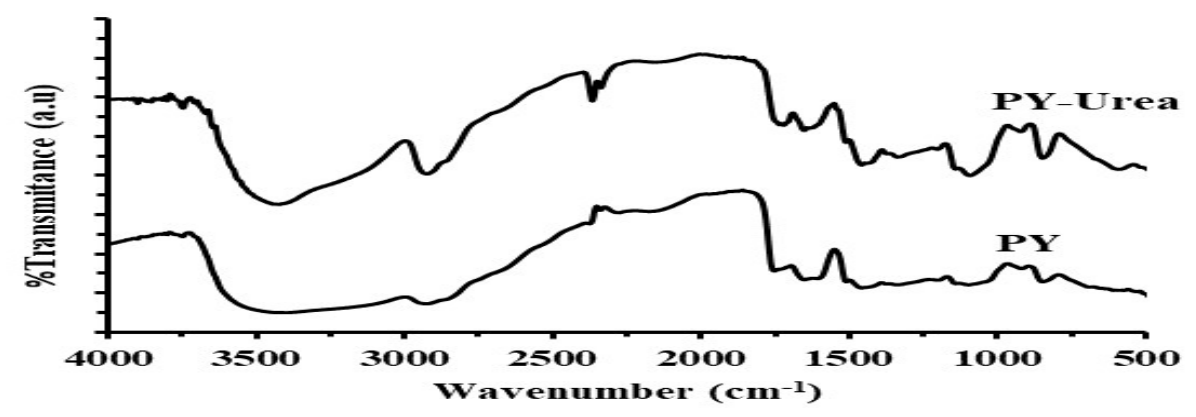

Fig.-3: Spectra Comparison of PPMEOA (PY) and PY-Urea

\section{Synthesis of Polyeugenol NIP Membrane}

From Fig.-4, we can see that urea gives a wider spectrum at the range of $400-1600 \mathrm{~cm}^{-1}$ as expected. ${ }^{13}$ NIP and MIP membranes provide a shift in the carbonyl spectrum into the greater direction indicating the presence of hydrogen bonds with urea. 
RASĀYAN J. Chem.

Vol. 14 | No. 2 |1165-1174| April - June | 2021

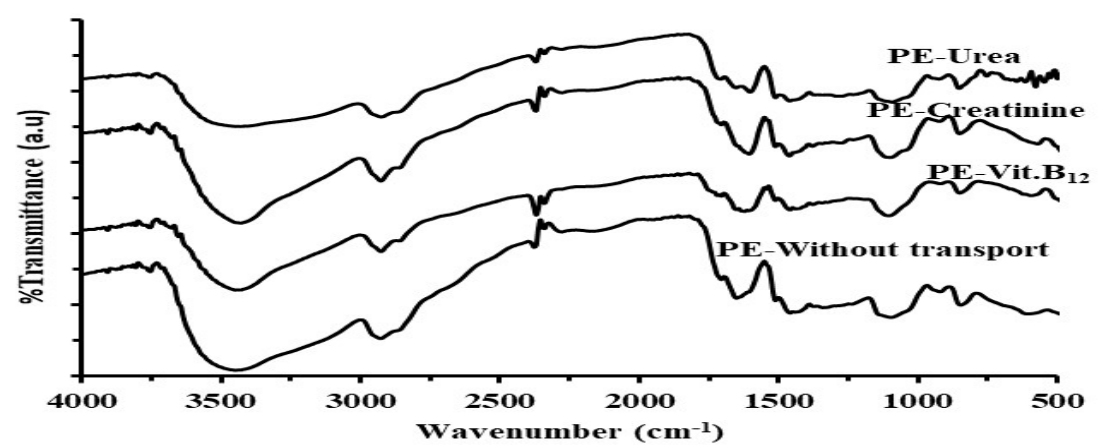

Fig.-4: IR Spectra of NIP Polyeugenol (PE) Membranes before and after Transport of Urea, Creatinine, and Vit. $\mathrm{B}_{12}$

\section{Synthesis of PPMEOA NIP}

In Fig.-5, we can see the appearance of NMP solvents spectrum in the range of $1670 \mathrm{~cm}^{-1}$ is lost due to heating and C-O glutaraldehyde and PVA in the range of $1100 \mathrm{~cm}^{-1} .6,13$ The transport results membrane develops an absorption of about $1604 \mathrm{~cm}^{-1}$ which indicates an interaction between $\mathrm{N}-\mathrm{H}$. This shows the interaction between the membrane and the molecules of urea, creatinine, and vitamin $\mathrm{B}_{12}$. Besides the appearance of absorption, the intensity resulted from each membrane that has been transported is different. The smallest intensity is produced in urea followed by creatinine and the last is vitamin $\mathrm{B}_{12}$. The IR spectra of MIP polyeugenol and MIP PPMEOA is shown in Fig.-6 and Fig.-7.

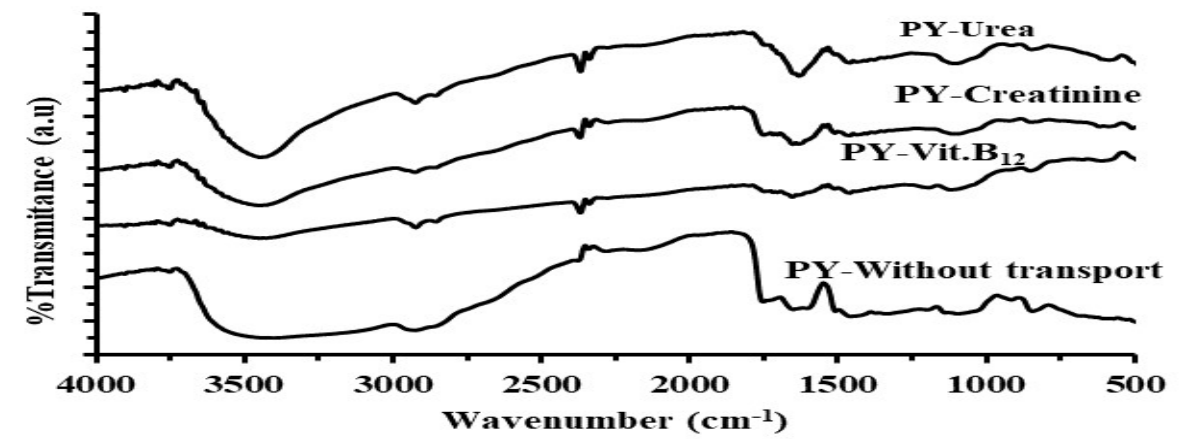

Fig.-5: IR Spectra of NIP PPMEOA (PY) Membranes before and after the transport of Urea, Creatinine, and Vit. B12

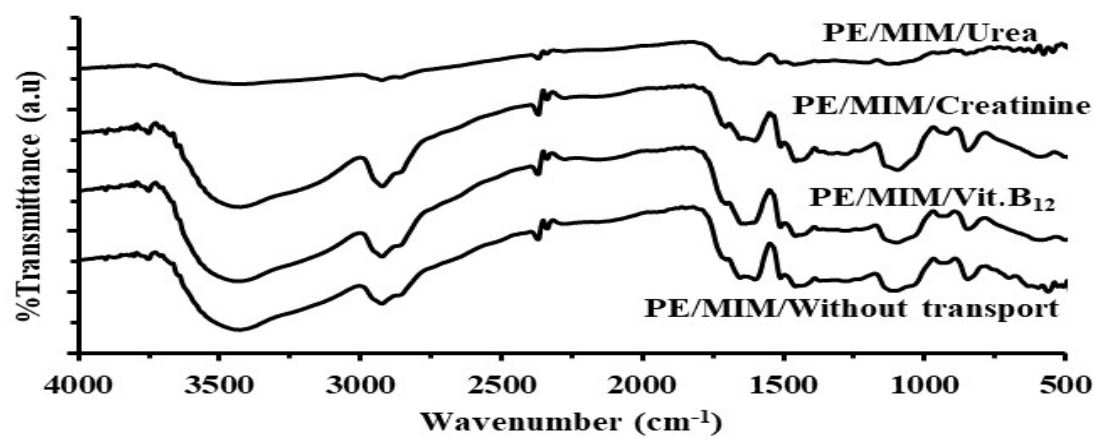

Fig.-6: IR Spectra of MIP Polyeugenol (PE) membranes before and after the transports

\section{Membrane Transport}

To evaluate the membrane performance, the transport of urea, creatinine dan vitamin $\mathrm{B}_{12}$ was performed. The concentration used for the urea transport was 300 ppm. It is shown in Fig.-8 that MIP membranes showed good transportability, particularly at the beginning. Past the 24 hours, MIP and NIP membrane showed similar ability in the transport of urea. This signifies the imprint effect in membranes. ${ }^{11}$ 
RASĀYAN J. Chem.

Vol. 14 | No. 2 |1165-1174| April - June | 2021

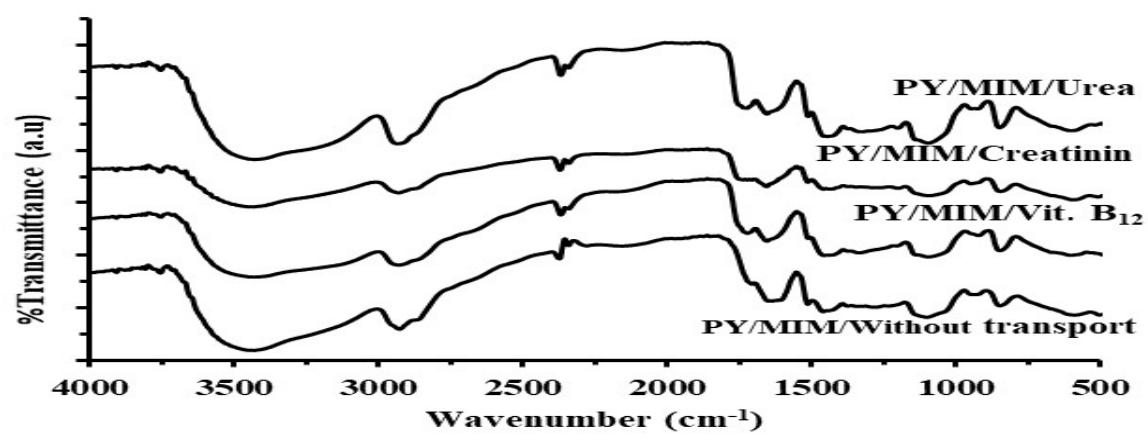

Fig.-7: IR Spectra of MIP PPMEOA (PY) Membranes before and after the transports
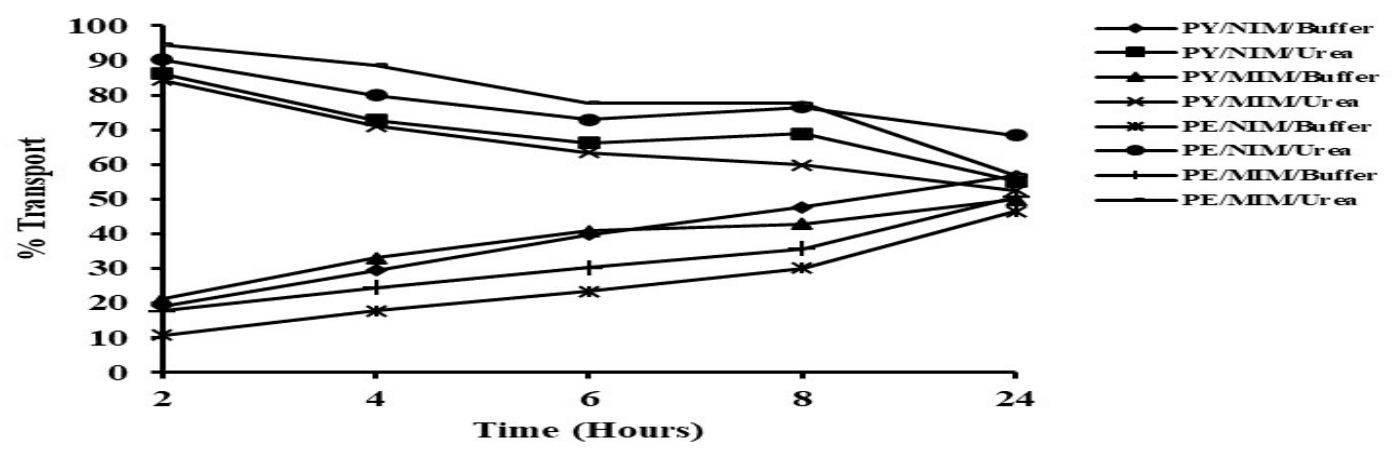

Fig.-8: Comparison of Urea transport between NIP and MIP of Polyeugenol (PE) and PPMEOA (PY) Membrane

Urea transport results as seen in Fig.-8 showed that NIP in PE has a smaller transport percentage compared to MIM. On the contrary, the PPMEOA NIM transport percentage is bigger compared to MIM.
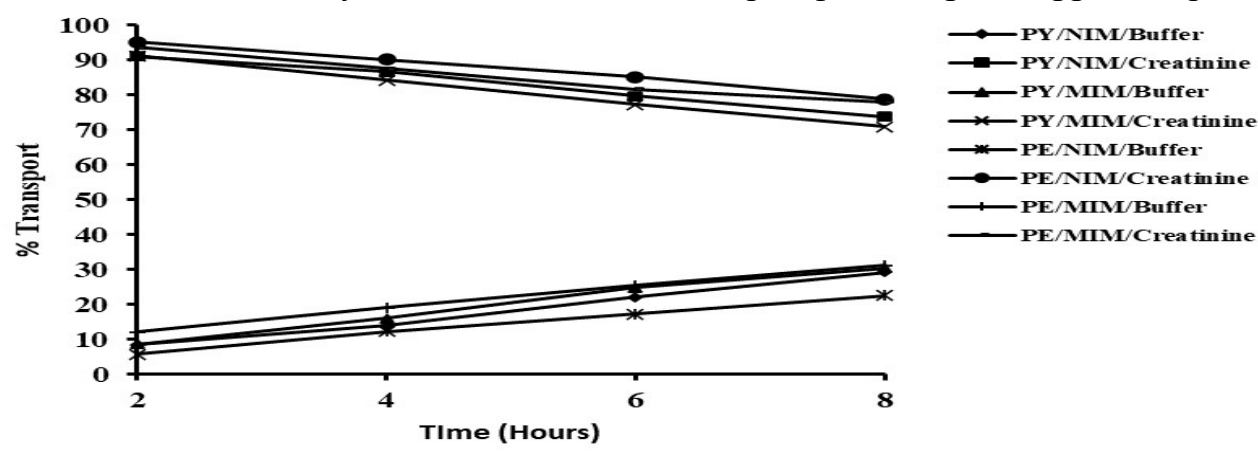

Fig.-9: Comparison of Creatinine transport between NIP and MIP of Polyeugenol (PE) and PPMEOA (PY) Membrane

Creatinine transport results are shown in Fig.-9, that the NIP in PE and PPMEOA has a smaller percentage of transport when compared to MIM.

Vitamin $\mathrm{B}_{12}$ transport results are shown in Fig.-10, that the NIP in PPMOA has a smaller percentage of transport compared to MIM. In contrast, for PE transport, the percent of NIM transport is greater than the MIM.

\section{Urea, Creatinine, and Vitamin $B_{12}$ Transport with a Variety of Groups on the Membrane}

Groups contained in membranes also affect transportability. This is evident from the urea transport shown in Fig.-11 below. Membranes with hydroxyl groups are more able to transport more urea than membranes with other groups. ${ }^{11}$ 
RASĀYAN J. Chem.

Vol. 14 | No. 2 |1165-1174| April - June | 2021

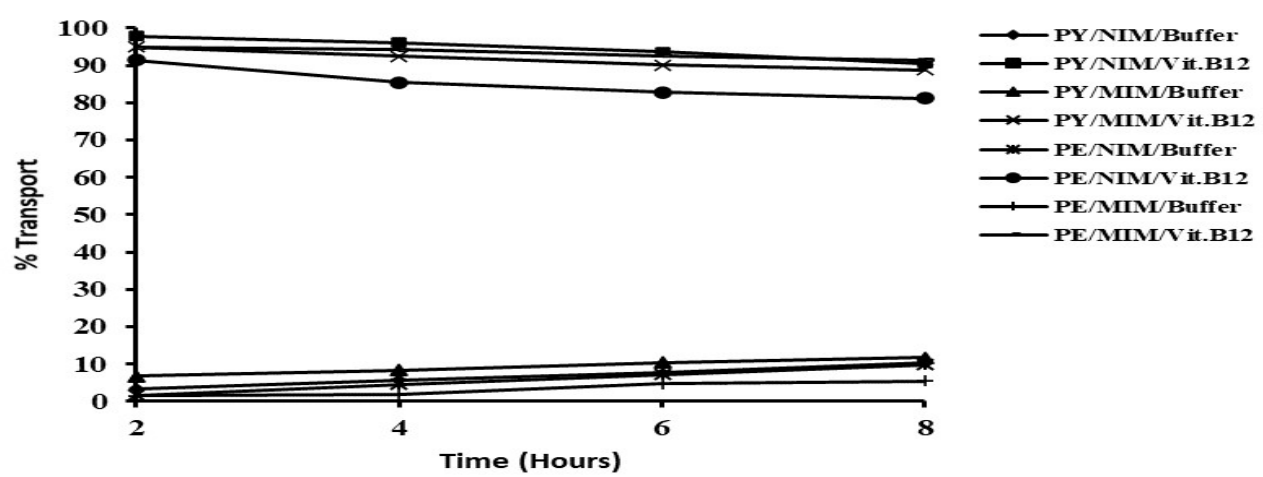

Fig.-10: Comparison of Vit $\mathrm{B}_{12}$ transport between NIP and MIP of Polyeugenol (PE) and PPMEOA (PY) Membrane
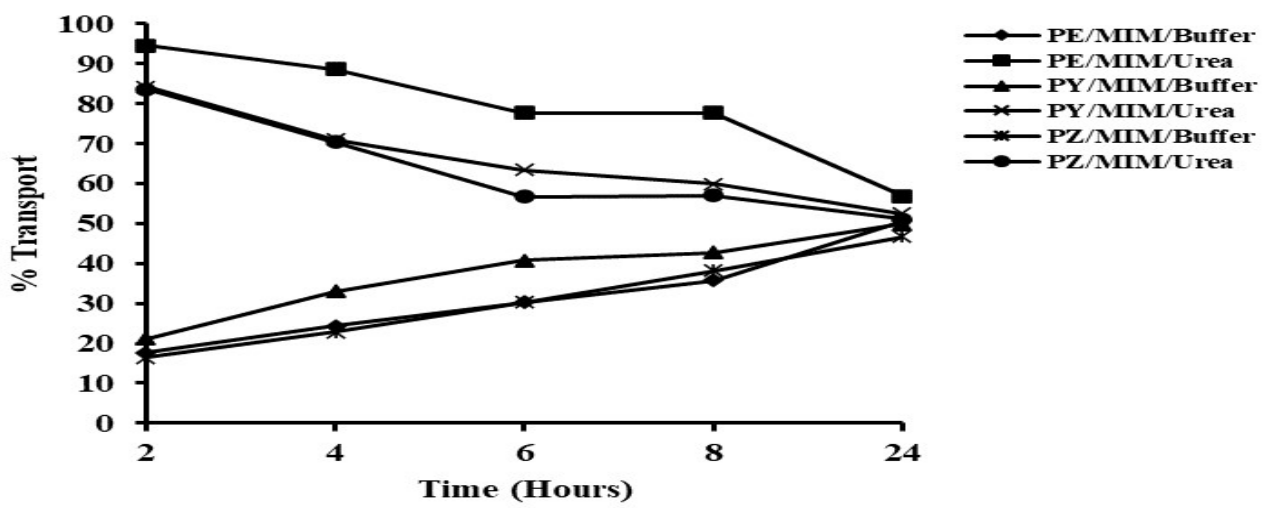

Fig.-11: Comparison of Group Differences towards Urea transport by Polyeugenol (PE), PPMEOA (PY), and PMTEEA (PZ) MIP Membrane

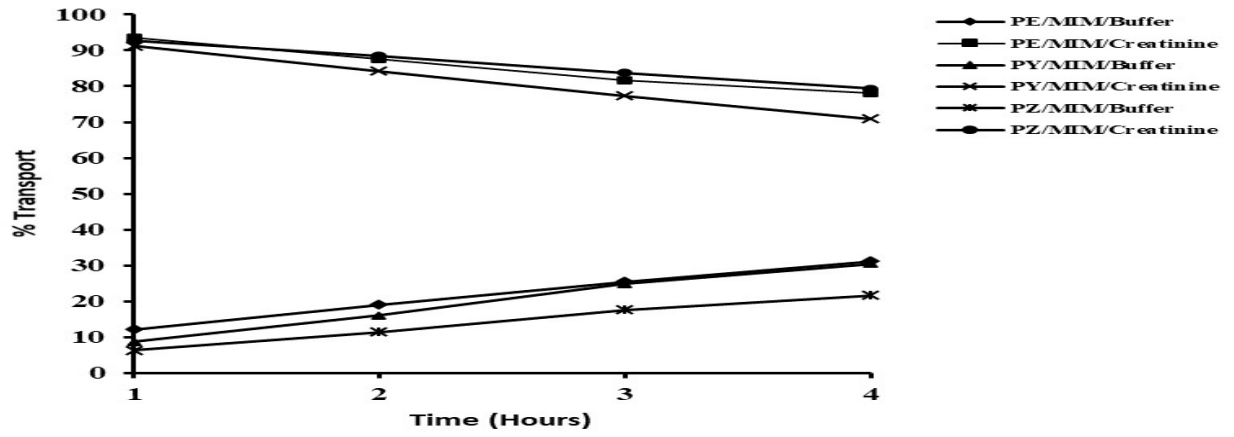

Fig.-12: Comparison of Group Differences towards Creatinine transport by Polyeugenol (PE), PPMEOA (PY), and PMTEEA (PZ) MIP Membrane

The results of the transports are shown in Fig.-11 and Fig.-12 that membranes that have hydroxyl groups are more capable of transporting urea than membranes that have pyridine and thiazole groups. In Fig.-13, the results show that membranes that have thiazole groups can transport the most vitamin $\mathrm{B}_{12}$ compared to pyridine and hydroxyl groups.

It is shown that the MIP membrane is also able to transport creatinine and vitamin $\mathrm{B}_{12}$, although not as large as urea. This is due to the difference in size between the molecules. Creatinine and vitamin $\mathrm{B}_{12}$ are bigger than urea. Urea has a size of 60 daltons, while vitamin $\mathrm{B}_{12}$ has a larger size of $8.5 \mathrm{~A}$ or $1.35 \mathrm{kDa}$. Meanwhile, creatinine has a size of 113 daltons. ${ }^{14,15}$ Creatinine transport lasts for 6 hours. After that, the creatinine becomes damaged marked by the reduction of the absorbance produced. 
RASĀYAN J. Chem.

Vol. 14 | No. 2 |1165-1174| April - June | 2021
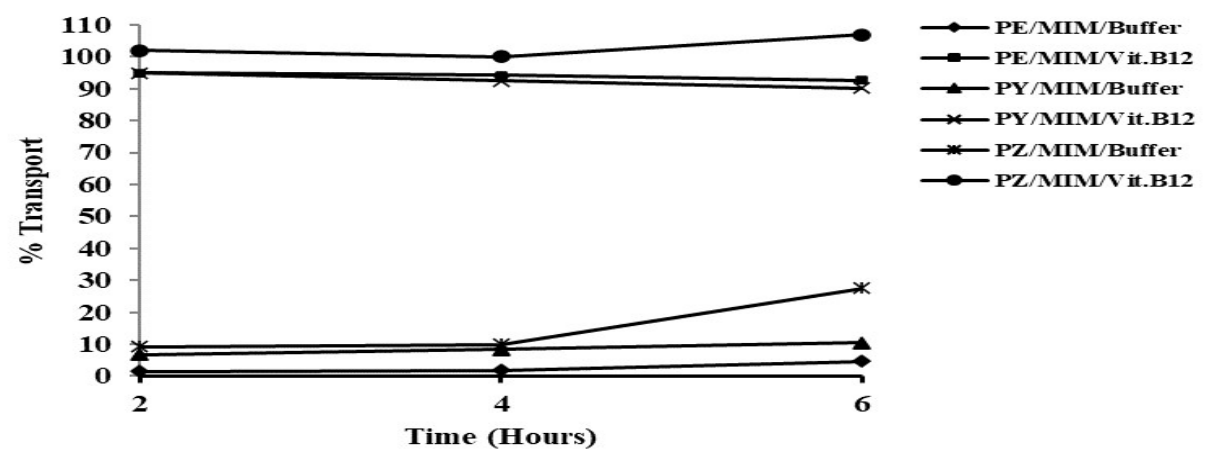

Fig.-13: Comparison of Group Differences towards Vit $\mathrm{B}_{12}$ transport by Polyeugenol (PE), PPMEOA (PY), and PMTEEA (PZ) MIP Membrane

\section{Membrane Characterization Using SEM EDX} Average Membrane Pore Diameter

Table-1 below is the average pore diameter of the PE and PPMEOA membranes. From the table above, the membrane that was used for transporting urea has a bigger pore than those that were used to transport creatinine and vitamin $\mathrm{B}_{12}$. The reason for the enlarging pore might be caused by the big amount of urea that was transported. SEM images are given in Fig.-14.

Table-1: Average Pore Diameter Size of PE and PPMEOA Membrane

\begin{tabular}{|c|c|c|c|c|c|}
\hline No. & Membrane & $\begin{array}{l}\text { Pore Diameter } \\
\text { Size }(\mu \mathrm{m})\end{array}$ & No. & Membrane & $\begin{array}{l}\text { Pore Diameter } \\
\text { Size }(\mu \mathrm{m})\end{array}$ \\
\hline 1. & PE/MIM/ Urea & 4.728 & 7. & PE/NIM/ Urea & 3.16 \\
\hline 2. & PE/MIM/ Creatinine & 3.022 & 8. & PE/NIM/ Creatinine & 2.354 \\
\hline 3. & PE/MIM/ Vit. B 12 & 4.132 & 9. & PE/NIM/ Vit. $B_{12}$ & 8.75 \\
\hline 4. & PY/MIM/ Urea & 3.478 & 10. & PY/NIM/ Urea & 6.116 \\
\hline 5. & PY/MIM/ Creatinine & None & 11. & PY/NIM/ Creatinine & 2.78 \\
\hline 6. & PY/MIM/ Vit. B 12 & 2.748 & 12. & PY/NIM/ Vit. B 12 & 3.69 \\
\hline
\end{tabular}

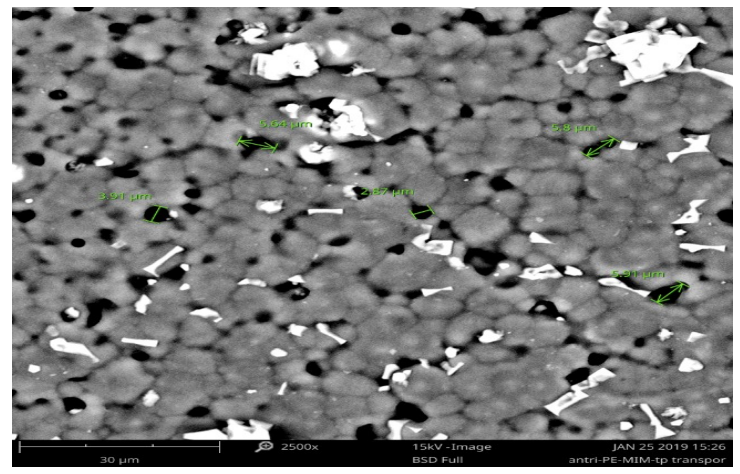

$\mathrm{PE} / \mathrm{MIM} /$ Without transport

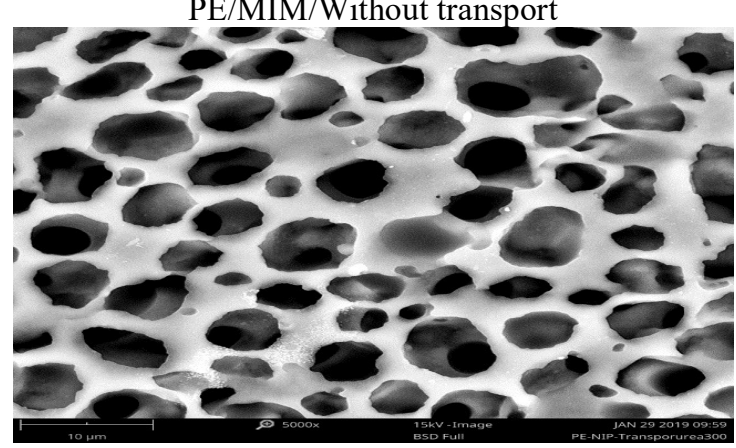

PE/MIM/Urea

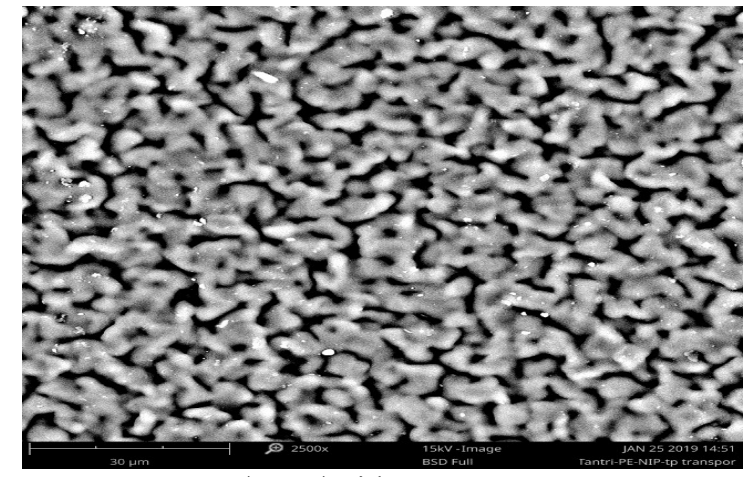

PE/NIM/Without transport

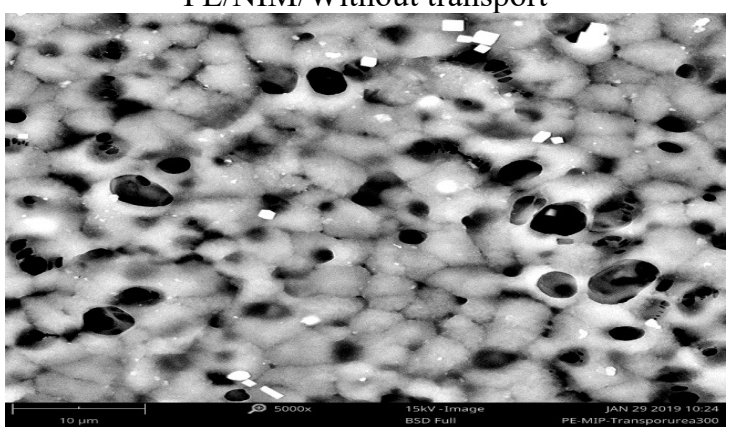

$\mathrm{PE} / \mathrm{NIM} / \mathrm{Urea}$ 
RASĀYAN J. Chem.

Vol. 14 | No. 2 |1165-1174| April - June | 2021

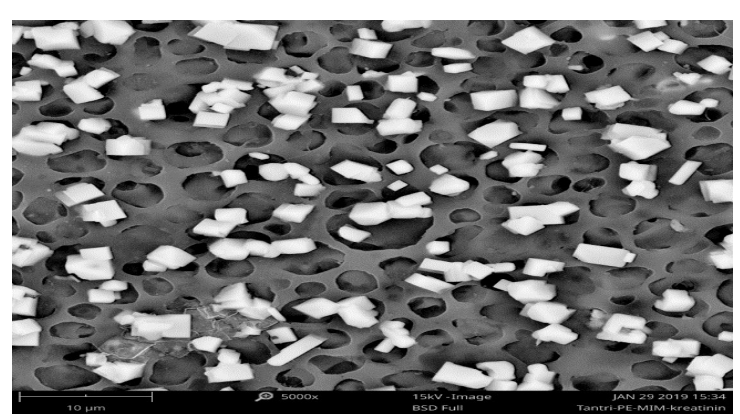

$\mathrm{PE} / \mathrm{MIM} /$ Creatinine

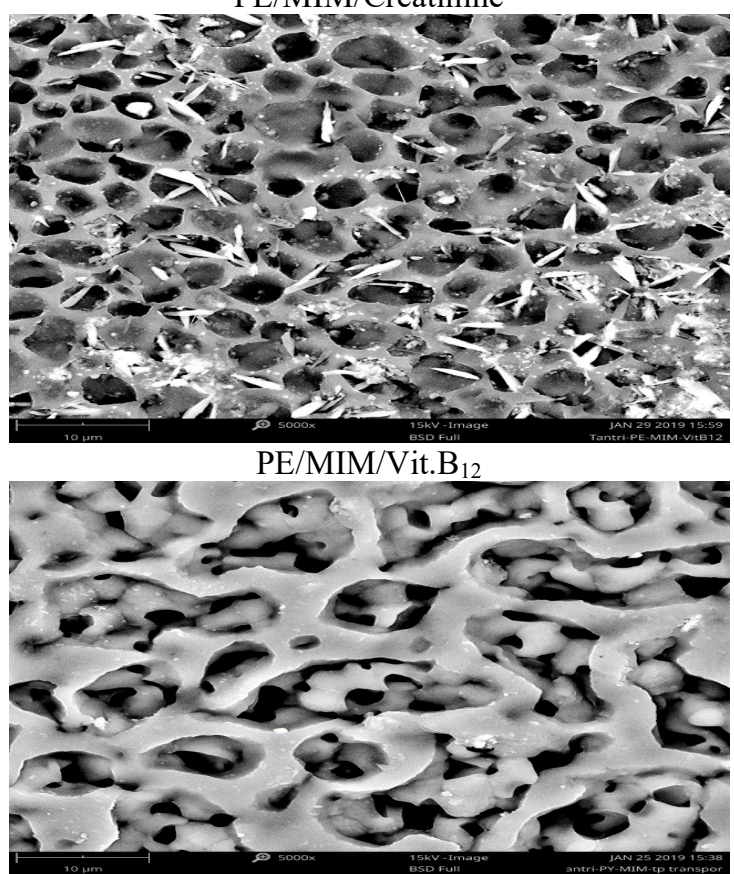

PY/MIM/Without transport
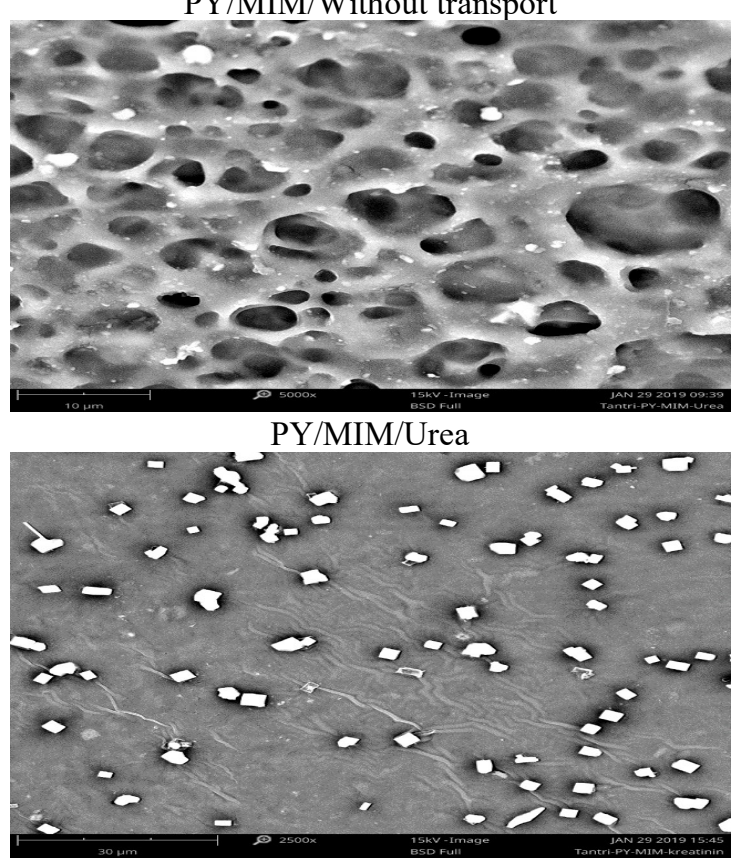

$\mathrm{PY} / \mathrm{MIM} /$ Creatinine
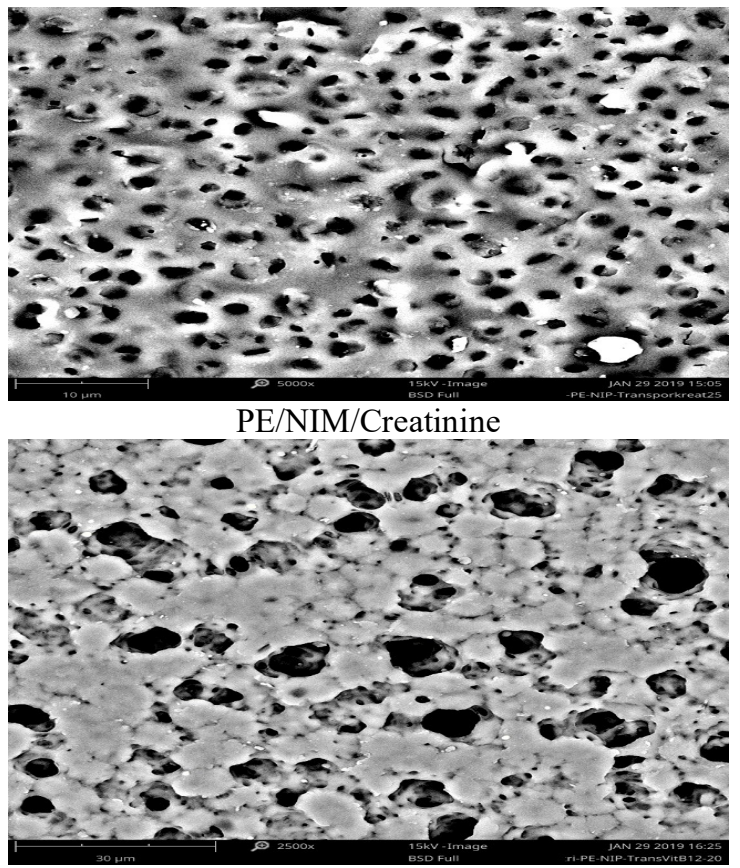

$\mathrm{PE} / \mathrm{NIM} / \mathrm{Vit}_{12}$

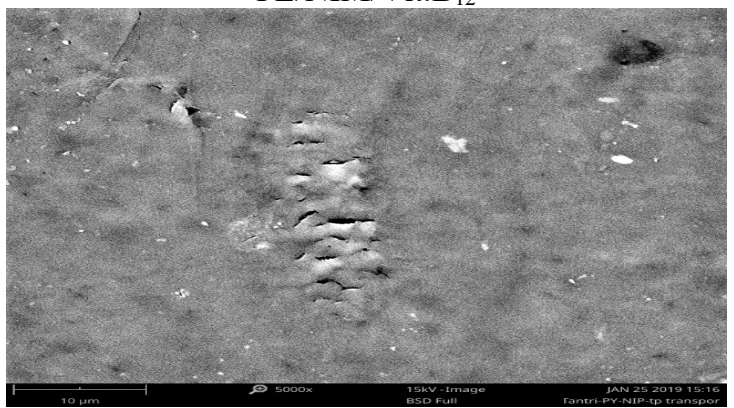

PY/NIM/Without transport

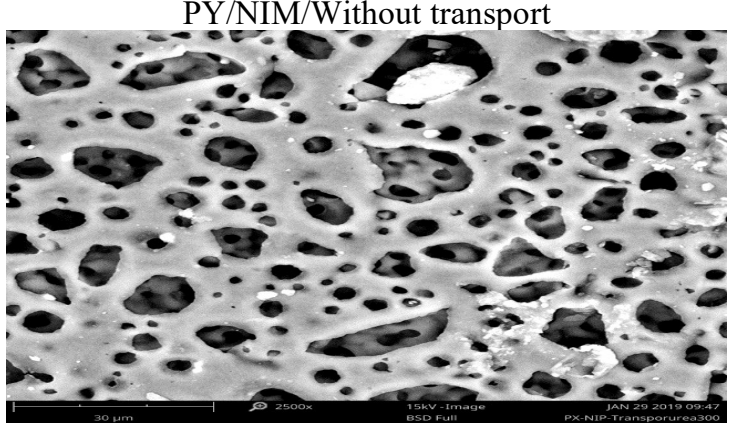

PY/NIM/Urea

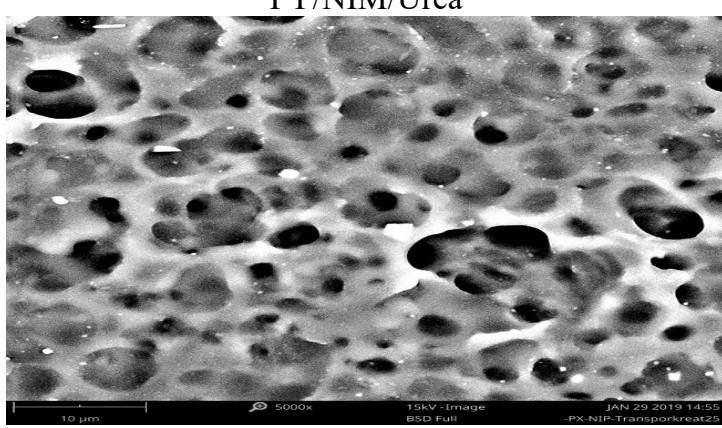

PY/NIM/Creatinine 


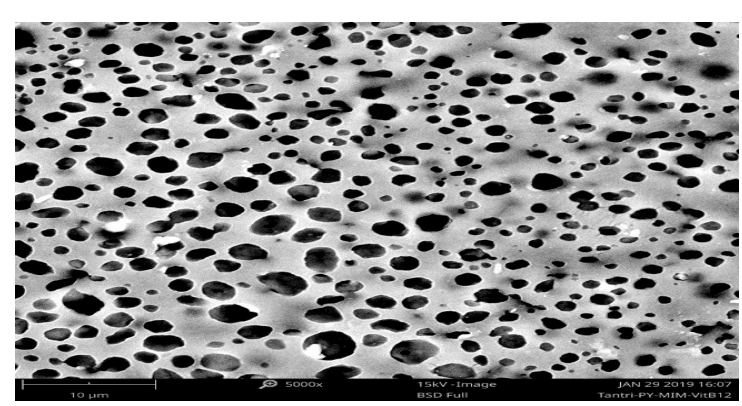

$\mathrm{PY} / \mathrm{MIM} / \mathrm{Vit} . \mathrm{B}_{12}$

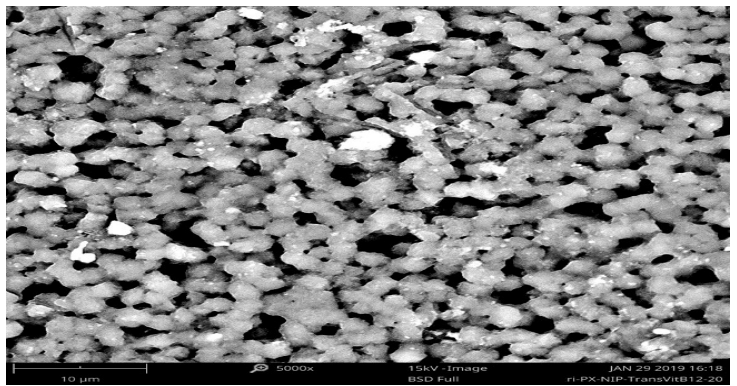

$\mathrm{PY} / \mathrm{NIM} / \mathrm{Vit} . \mathrm{B}_{12}$

Fig.-14: SEM Images Comparison of Membranes without transport and those that have been used to transport Urea, Creatinine, and Vitamin $\mathrm{B}_{12}$ Solutions

\section{CONCLUSION}

1. Urea transport have the best result when carried out using a membrane with a hydroxyl group (polyeugenol).

2. Membrane with thiazole group (PMTEEA) have better transport performance for vitamin $\mathrm{B}_{12}$ and creatinine in comparison to urea.

\section{ACKNOWLEDGEMENT}

The authors would like to thank The Ministry of Research, Technology, and Higher Education of the Republic of Indonesia for the 2018 Post-Doctoral Grants.

\section{REFERENCES}

1. C. Amri, Mudasir, D. Siswanta, R. Roto, Indonesian Journal of Chemistry, 15(2), 146(2015), DOI: $10.22146 / \mathrm{ijc} .21208$

2. I.G. Wenten, P.T.P. Aryanti, Khoiruddin, A.N. Hakim, N.F. Himma, Journal of Membrane Science \& Research, 2(2), 78(2016), DOI:10.22079/JMSR.2016.19155

3. R.A. Lusiana, D. Siswanta, Mudasir, T. Hayashita, International Journal of Chemical Engineering and Applications, 4(4), 22 (2013), DOI:10.7763/IJCEA.2013.V4.301

4. E. Nurhayati, S. Hartoyo, S. Mulatsih, Jurnal Ekonomi dan Kebijakan Pembangunan, 7(1), 21 (2018), DOI:10.29244/jekp.7.1.21-42

5. B.L. Tian, Q.Z. Liu, Z.L. Liu, P. Li, J.W. Wang, Journal of Economic Entomology, 108(3), 957(2015), DOI: 10.1093/jee/tov075

6. M.C. Djunaidi, Jumina, D. Siswanta, M. Ulbricht, Asian Journal of Chemistry, 27(12), 4553(2015), DOI: 10.14233/ajchem.2015.19228\#sthash.LfxtS8sz.dpuf

7. M.C. Djunaidi, Jumina, D. Siswanta, M. Ulbricht, Indonesian Journal of Chemistry. 15(3), 305(2015), DOI: $10.22146 /$ ijc. 21200

8. M.C. Djunaidi, Jumina, D. Siswanta, M, Ulbricht, Oriental Journal of Chemistry, 32(1), 77(2016), DOI: $10.13005 / \mathrm{ojc} / 320107$

9. M.C. Djunaidi, Y. Astuti, Rasayan Journal of Chemistry, 12(2), 809(2019), DOI: $10.31788 /$ RJC.2019.1225120

10. M.C. Djunaidi, D. Siswanta, Jumina, In Proceedings of $9^{\text {th }}$ Joint Conference on Chemistry, Semarang, Indonesia, pp. 251-257 (2014).

11. M.C. Djunaidi, I.G. Wenten, In Proceedings of $13^{\text {th }}$ Joint Conference on Chemistry, Semarang, Indonesia, 509, p. 01206(2019), DOI:10.1088/1757-899X/509/1/012069

12. Z. Piasek, Urbanski, Bulletin de L'Academie Polonaise Des Sciences, X(3), 113(1962).

13. S.G. Anicuta, L. Dobre, M. Stroescu, I. Jipa, Analele Universitătii din Oradea Fascicula: Ecotoxicologie, Zootehnie si Tehnologii de Industrie Alimentară, 1234 (2010).

14. A.O. Hosten, BUN and Creatinine. Clinical Methods: The History, Physical and laboratory Examinations, $3^{\text {rd }}$ edition, Butterworths, Boston (1990).

15. C. Talmard, L. Guilloreau, Y. Coppel, H. Mazarguil, P. Faller, ChemBioChem, 8(2), 163(2007), DOI: $10.1002 /$ cbic. 200600319

[RJC-6133/2020] 